Nevşehir Bilim ve Teknoloji Dergisi Cilt 5(1) 16-26 2016

DOI: $10.17100 /$ nevbiltek.90629

URL: http://dx.doi.org/10.17100/nevbiltek.90629

\title{
Ağrı İlinde Küçükbaş Hayvancılığın Mevcut Durumu, Sorunları ve Çözüm
}

\section{Önerileri}

\author{
Zeki Şahinler $^{1, *}$, Yücel Demir ${ }^{1}$ \\ ${ }^{1}$ A ğrı İbrahim Çeçen Üniversitesi Celal Oruç Hayvansal Üretim Yüksekokulu, 04600 Eleşkirt, Ağrl,
}

$\ddot{\mathbf{O z}}$

Bu çalışmada, 2004 - 2014 yılları arasındaki veriler kullanılarak Ağrı ili küçükbaş hayvan varlığının durumu incelenmiş, sorunları ve çözüm önerileri ortaya konulmuştur. Söz konusu dönem içerisinde ilin küçükbaş hayvan varlığında önemli değişikliklerin meydana geldiği gözlenmiştir. 2014 yılındaki küçükbaş hayvan varlığı 2004 yılı ile mukayese edildiğinde toplam koyun sayısında \% 14.36’lık bir azalma keçi sayısında ise \% 6.60’lık bir artış göstermiştir. 2014 yılı TÜiK verilerine göre ildeki küçükbaş hayvan varlığı, ülke küçükbaş hayvan varlığının \% 3.5'ini ve tamamının yerli ırklardan oluştuğu tespit edilmiştir. Yine aynı verilere göre Türkiye'de kırmızı et, deri, süt, yapağı ve kıl üretimine ilin katkısı sırasıyla \% 3.8, \% 3.2, \% 3.6, \% 4.8 ve \% 1.0 olarak bulunmuştur.

Küçükbaş hayvan ve ürünlerinin pazarlama problemlerinin olması, mevcut küçükbaş hayvan barınaklarının yetiştiricilik için uygun olmaması, meraların verim düşüklüğü, yem bitkileri tarımının yetersiz ve plansız yapılması ildeki başlıca problemleri oluşturmaktadır. Küçükbaş hayvansal ürünlerin pazar talepleri dikkate alınarak planlanıp üretilmesi ve tüketiciye en kısa yoldan ulaştırılmasını sağlayacak istikrarı bir sistemin kurulması, hayvan sağlığına uygun çevre ve barınakların yapımını özendirecek nitelikte destek verilmesi, meraların ıslah uygulamalarının hayata geçirilmesi problemlerin çözümüne katkı sağlayacaktır.

Anahtar kelimeler: Ağrı, küçükbaş hayvan, et, süt, üretim

\section{The Existing Conditions, Its Problems and Suggested Solutions for Small Animal Breeding in Ağrı Province}

\begin{abstract}
By using the data collected between 2004-2014 years, the existing problems of small animal breeding is identified and solutions are suggested for related problems in Ağrı province. In this period, significant changes have been observed in small animal population. When the small animal population in 2014 is compared to 2004, it has been found that the number of sheep decreased by $14.36 \%$ while the number of goats increase by $6.60 \%$. According to TÜiK data 2014, small animal population comprises $3.5 \%$ of whole country small animal population. This population is made up domestic breeds. Again according to the same data, in the whole country the contribution of the province to red meat, leather, milk, wool, and goat hair is 3.8 \%, 3.2 \%, 3.6 \%, $4.8 \%$ and $1.0 \%$ respectively.

Major problems in the city are as follows: marketing problems of small animals and their products, unsuitable small animal shelters for breeding, low yielding pastures, insufficient and unplanned agriculture of the feeding plants. Planning and producing small animal products according to market demands, creating a stable system to deliver to the consumers within an efficient and shortest way and as well as giving incentives to promote for building suitable environments and shelters for animal health and reorganizing pasture improvements would help in application of right solutions.
\end{abstract}

Keywords: Ağr1, small animal, meat, milk, production

* e-mail: zsahinler@agri.edu.tr 


\section{Giriş}

Dünya'da hayvancıllk sektörü, ülkelerin önemli ekonomik faaliyet alanlarından birisi olduğu bilinmektedir [1]. Türkiye'de de dünyada olduğu gibi küçükbaş hayvan yetiştiriciliğinin özel bir yeri vardır. Çünkü koyun ve keçiler verimsiz meralarla nadas, anız ve bitkisel üretime uygun olmayan, başka türlerin yararlanamadığı alanları değerlendirerek et, süt, yapağı, kıl ve deri gibi ürünlere dönüştürülebilme yeteneğine sahiptirler [2]. 2014 yılı itibarı ile Türkiye de üretilen toplam (1.008.272 ton) kırmızı etin \% 12.47’si, toplam (18.630.859 ton) sütün \% 8.47’si, toplam(10.481.985 adet) derinin \% 64.56's1 küçükbaş hayvansal üretimden karşılanmaktadır. Ayrıca 64.144 ton yapağı, tiftik ve kıl kü̧̈ükbaş hayvancılıktan sağlanmaktadır [3].

Türkiye küçükbaş hayvan varlığı bakımından dünyada önde gelen ülkelerden biri olmasına rağmen hayvan başına sağlanan verim açısından beklentileri karşılamaktan uzaktır. Ancak ülkemizin ekolojik koşulları küçükbaş hayvancılığa uygundur [4]. Küçükbaş hayvanc1lıktan elde edilen gelirler arasında canlı hayvan satışı, yapağı ve kı1, çiğ süt, tereyağı ve peynir satışı yer almaktadır [5].

Türkiye küçükbaş hayvancılığı; popülasyonu büyük oranda düşük verimli yerli ırklardan oluşan, besleme koşulları ağırlıklı olarak otlatmaya dayalı ve sınırlı girdi ile üretimin hedeflendiği ekstansif bir yapıya sahiptir [6]. Sektörün bu özelliklerine; işletmelerin kü̧̈ük ve cılız bir yapıya sahip olması, girdi temini, ürün pazarlama ve değerlendirme olanaklarının yetersizliği, buna bağlı olarak üreticinin pazar fiyatından düşük pay alması, üretimin büyük ölçüde geçimlik olarak yapılması da eklenebilir [7].

Yüzölçümü 11.376 km² olan Ağrı; sahip olduğu mera varlığı (542.731 ha) ile Doğu Anadolu Bölgesinde 2. ve ülke genelinde ise 4. sıradadır. 1500-2400 metre arasında değişen yükseklikteki yayla ve ovalardan oluşur. İl merkezinin denizden yüksekliği 1.632 metredir. İl; 8 ilçe, 4 belde, 567 köy ve 255 mezradan oluşmaktadır. Genel olarak halkın geçim kaynağı tarım ve hayvancılıktır. İlin nüfusu 555.479 olup, nüfusun \% 47.63’ü köylerde, \% 52.37'si şehirlerde yaşamaktadır. Nüfusun \% 73’ü tarımla uğraşmaktadır. Ağrı, ülkemizin önemli bir hayvancılık merkezidir. İlin ekonomisi hayvansal üretim ve ürünlerinin satışına dayanır. İlin coğrafi yapısı itibariyle geniş yayla ve meralara sahip olması, toprağın tarıma fazla elverişli olmaması nedeniyle küçükbaş hayvancıllk büyük oranda yaygınlaşmıştır [8].

Türkiye kırmızı et ve deri üretiminde ilin payı sırasıyla \% 3.8 ve \% 3.2'dır. Diğer yandan 2014 yılı itibariyle Türkiye süt üretiminin \% 3.6'sı, yapağı üretiminin \% 4.8'i ve kıl üretiminin \% 1.0'1 Ağrı'da üretilmektedir [3]. Söz konusu oranlardan da anlaşıldığı gibi, Türkiye de hayvansal üretime ilin katkısının yeterli olduğu söylenemez. Buna rağmen Ağrı İl'i özellikle küçükbaş hayvan varlığı ve istihdamdaki yeri itibarıyla bölgede dikkat çekici bir yapıya sahiptir. Mevcut potansiyel göz önünde bulundurulduğunda Ağrı'nın hayvansal ürün üretiminde de öncü illerden biri olması gerektiği ortaya çıkmaktadır. Ancak Türkiye hayvanc1lığı için sözü edilen sorunlar, ilde de kaynakların etkin ve doğru bir şekilde kullanılmamasına bağlı olarak birebir yaşanmaktadır. Ağrı İl’inde, küçükbaş hayvansal ürünlerin (et, süt, deri vb.) bir pazarlama sistemine sahip olmaması, barınakların yetiştirme şartlarına elverişli olmaması, mera kalitesinin düşük olması gibi temel sorunlara bağlı olarak, sektör gereken seviyenin çok gerisindedir. Ağrı İl’inde, küçükbaş hayvansal ürünlerin pazar talepleri dikkate alınarak planlanıp üretilmesi ve tüketiciye en kısa yoldan ulaştırılmasını sağlayacak istikrarlı bir sistemin kurulması, hayvan sağlığına uygun çevre ve barınakların yapımını özendirecek nitelikte desteklenmesi, meraların ıslah 
uygulamalarının hayata geçirilmesi ile halkının önemli bir geçim kaynağını oluşturan küçükbaş hayvan yetiştiriciliğinde, beklenen gelişmelerin gerçekleşe bileceği öngörülmektedir.

$\mathrm{Bu}$ nedenle, Ağrı İl'inde mevcut küçükbaş hayvancılık işletmelerinin genel durumlarını ve üretim düşüklüğüne yol açan sorunları belirlenerek çözüm önerilerinde bulunmak amacıyla bu çalışma planlanmıştır.

\section{Materyal ve Yöntem}

Bu çalı̧̧manın verileri Türkiye İstatistik Kurumu (TUIK), Ağrı İl Gıda, Tarım ve Hayvancılık Müdürlüğü, Ağrı İl Gıda, Tarım ve Hayvancıllk Müdürlüğü Hayvan Sağlığı, Yetiştiriciliği ve Su Ürünleri Şubesi Müdürlüğü ve Bitkisel Üretim ve Bitki Sağlı̆̆ı Şube Müdürlüğü verilerinden temin edilmiştir. Bu veriler, y1llara göre değerlendirilerek elde edilen bulgular tablolar şeklinde sunulmuştur.

\section{Araştırma Bulguları}

\section{1. İlin Arazi Yapısı}

2014 TÜiK verilerine göre, Ağrı İl’i Türkiye'de kaba yem üretiminde 3. ve çayır- mera alanı olarak da 4. sıradadır. İlde 11.497 adet kayıtlı koyunculuk işletmesinde 1.452 .572 baş koyun, keçi olup; her işletmeye ortalama 126 baş koyun, keçi düşmektedir. İlde ortalama işletme büyüklüğü 103 dekar, bir işletme ortalama 5 parselden oluşmaktadır [9]. İl ve ilçelerin arazi yapısı ile ilgili veriler Tablo.1'de verilmiştir [8].

Tablo 1. Ağrı İl’i ve İlçelerinin Arazi Yapısı

\begin{tabular}{|c|c|c|c|c|c|}
\hline İlçeler & $\begin{array}{c}\text { Yüzölçümü } \\
\text { (ha) }\end{array}$ & $\begin{array}{c}\text { Tarım Alanı } \\
\text { (ha) }\end{array}$ & $\begin{array}{l}\text { Çayır Mera } \\
\text { Alanı (ha) }\end{array}$ & $\begin{array}{c}\text { Yayla Alanı } \\
\text { (ha) }\end{array}$ & $\begin{array}{c}\text { Tarıma Elverişsiz } \\
\text { Alan (ha) }\end{array}$ \\
\hline Merkez & 178.100 & 72.000 & 83.879 & 16.230 & 5.991 \\
\hline Diyadin & 127.400 & 37.000 & 61.065 & 18.272 & 10.063 \\
\hline Doğubayazıt & 238.300 & 45.500 & 122.368 & 57.695 & 12.737 \\
\hline Eleşkirt & 125.900 & 50.700 & 58.769 & 11.346 & 5.095 \\
\hline Hamur & 89.800 & 18.300 & 59.679 & 8.000 & 3.821 \\
\hline Patnos & 142.100 & 63.000 & 60.438 & 12.000 & 6.662 \\
\hline Taşlıçay & 79.800 & 24.500 & 35.264 & 8.200 & 12.836 \\
\hline Tutak & 156.200 & 50.000 & 61.269 & 37.607 & 7.324 \\
\hline Toplam & 1.137 .600 & 361.000 & 542.731 & 169.550 & 64.319 \\
\hline
\end{tabular}

Tablo.1 incelendiğinde, Ağrı İl'inin sahip olduğu 1.137.600 ha toplam arazi varlığının \% 32'sini tarım alanları, \% 48'ini çayır ve mera alanları, \% 15'ini yayla alanları geri kalan \% 5'ini de tarıma elverişsiz alanlardan oluşmaktadır. En fazla çayır mera ve yayla alanı, kü̧̈ükbaş hayvan yetiştiriciliğinin de en yoğun yapıldığı Doğubayazıt ilçesinde bulunmaktadır. İlde bitkisel üretim yapan işletmeler aynı zamanda hayvansal üretim işletmesi olarak da faaliyet göstermektedirler. $\mathrm{Bu}$ tip işletmelerin, üretim maliyetini düşürme ve pazarlama açısından yeterince başarılı oldukları söylenemez. Üreticilerin büyük bir kısmı yeterince kaba yem üretimi yapmadan hayvancılıkla meşgul olmaktadır. 2014 verilerine göre 
toplam tarım alanının \% 67.5'i tahıl ve diğer bitkisel üretim, \% 32.0’si nadas, \% 0.5’i ise sebze ve meyve üretim alanı olarak kullanılmaktadır [10].

\subsection{Küçükbaş Hayvan Varlığı}

Tablo.2'de ilin küçükbaş hayvan varlığı incelendiğinde, 2014 yılında 1.346 .303 baş koyun 106.269 baş keçi varlığına sahip olduğu, 2004'den 2009 yılına doğru \% 26 düzeyinde önemli bir azalma, 2009'dan 2014'e doğru \% 48'lik bir toparlanma görülmektedir [3]. Türkiye'de de küçükbaş hayvan varlığ1 ilin durumuyla benzerlik göstermektedir. 2004'den 2009'a doğru bir düşüş, 2009'dan 2014'e doğru ise bir artış söz konusudur. İlin küçükbaş hayvan varlığının Türkiye içindeki payı ise \% 5.3’den \% 3.5'e düştüğü görülmektedir. Yıllar içinde yükselme eğilimi sevindirici olmakla birlikte, ilin sahip olduğu potansiyel düşünüldüğünde bu rakamlar tatmin edici değildir. Ülke genelindeki hayvan sayısındaki hızlı artışında bu oranın bu şekilde oluşmasına sebep düşünülmektedir.

Tablo 2. Türkiye'de ve Ağrı'da Türlere Göre Küçükbaş Hayvan Sayıları (Baş)

\begin{tabular}{|c|c|c|c|c|c|c|c|}
\hline & & AĞRI & & & ÜRKIIYE & & \\
\hline Yillar & $\begin{array}{c}\text { Koyun } \\
\text { (Yerli) } \\
\text { (Baş) }\end{array}$ & $\begin{array}{c}\text { Keçi (Kıl) } \\
\text { (Baş) }\end{array}$ & $\begin{array}{c}\text { Toplam } \\
\text { (Baş) }\end{array}$ & $\begin{array}{c}\text { Koyun (Yerli- } \\
\text { Merinos) } \\
\text { (Baş) }\end{array}$ & $\begin{array}{c}\text { Keçi (Kıl- } \\
\text { Tiftik) } \\
\text { (Baş) }\end{array}$ & $\begin{array}{c}\text { Toplam } \\
\text { (Baş) }\end{array}$ & $\begin{array}{c}\text { Oran } \\
(\%)\end{array}$ \\
\hline 2004 & 1.571 .971 & 99.252 & 1.671 .223 & 25.201 .155 & 6.609 .937 & 31.811 .092 & 5.3 \\
\hline 2005 & 1.352 .664 & 94.437 & 1.447.101 & 25.304.325 & 6.517 .464 & 31.821.789 & 4.5 \\
\hline 2006 & 1.265 .140 & 107.830 & 1.372 .970 & 25.616.912 & 6.643 .294 & 32.260 .206 & 4.3 \\
\hline 2007 & 1.200 .760 & 111.200 & 1.311 .960 & 25.462.293 & 6.286 .358 & 31.748 .651 & 4.1 \\
\hline 2008 & 990.270 & 93.085 & 1.083 .355 & 23.974.591 & 5.593 .561 & 29.568.152 & 3.7 \\
\hline 2009 & 892.510 & 86.588 & 979.098 & 21.749.508 & 5.128 .285 & 26.877.793 & 3.6 \\
\hline 2010 & 1.064 .105 & 96.383 & 1.160 .488 & 23.089.691 & 6.293 .233 & 29.382.924 & 3.9 \\
\hline 2011 & 985.104 & 114.834 & 1.099 .938 & 25.031 .565 & 7.277 .953 & 32.309 .518 & 3.4 \\
\hline 2012 & 1.185 .709 & 121.295 & 1.307 .422 & 27.425.233 & 8.357.286 & 35.782 .519 & 3.7 \\
\hline 2013 & 1.240 .180 & 122.295 & 1.362 .475 & 29.284.247 & 9.225 .548 & 38.509 .795 & 3.5 \\
\hline 2014 & 1.346 .303 & 106.269 & 1.452 .572 & 31.140 .244 & 10.344 .936 & 41.485 .180 & 3.5 \\
\hline
\end{tabular}

Bu yüzden, Ağrı İl’i mevcut haliyle Türkiye’nin küçükbaş hayvan varlığı içinde (2014) \% 3.5 gibi önemli bir paya sahiptir. Sahip olunan koyun varlığı başta Morkaraman, Morkaraman x Akkaraman melezleri ve Akkaraman yerli koyun ırklarından, keçi de Kıl Keçisi ırklarından oluşmaktadır. Bu durum Ağrı İl’i ve çevresinde küçükbaş hayvan yetiştiriciliğinde ıslah çalışmalarına ihtiyaç duyulduğunu göstermektedir[11]. Bu amaçla Gıda, Tarım ve Hayvancılık Bakanlığı, Tarımsal Araştırmalar ve Politikalar Genel Müdürlüğü (TAGEM)'nün koordinatörlüğünde ülke genelinde yürütülmekte olan "Halk Elinde Küçükbaş Hayvan Islahı Ülkesel Projesi” il genelinde yetiştiriciliği yapılan Morkaraman ırkının özellikleri korunarak geliştirilmesi için, 2013 yılında başlatılmıştır.

Ağrı merkez ve ilçeler düzeyinde küçükbaş hayvan varlığı Tablo.3'de verilmiştir. Doğubayazıt 2014 yılı itibarı ile toplam 558.946 baş ile 1. sırada yer alırken, Eleşkirt 52.597 baş ile son sırada yer almıştır. 2004-2014 yılları arasında küçükbaş hayvan sayılarında; ilçeler düzeyinde \% 53 oranında en fazla artış Doğubayazıt ilçesinde görülürken, \% 73 oranında en fazla düşüş Eleşkirt ilçesinde görülmüştür. 
Şahinler Z., Demir Y.

Tablo 3. Ağrı İl ve İlçeler İtibariyle Türlere Göre Küçükbaş Hayvan Sayıları (Baş)

\begin{tabular}{|c|c|c|c|c|c|c|c|c|c|c|c|c|}
\hline & & 2004 & 2005 & 2006 & 2007 & 2008 & 2009 & 2010 & 2011 & 2012 & 2013 & 2014 \\
\hline \multirow{3}{*}{ Merkez } & Koyun (Yerli) & 220.560 & 203.450 & 280.000 & 266.600 & 182.720 & 100.500 & 94.440 & 101.080 & 96.275 & 98.413 & 97.839 \\
\hline & Keçi (Kıl) & 16.860 & 15.555 & 21.000 & 19.040 & 13.870 & 7.193 & 6.275 & 4.295 & 4.225 & 4.375 & 3.861 \\
\hline & Toplam & 237.420 & 219.005 & 301.000 & 285.640 & 196.590 & 107.693 & 100.715 & 105.375 & 100.500 & 102.788 & 101.700 \\
\hline \multirow{3}{*}{ Diyadin } & Koyun (Yerli) & 325.098 & 265.750 & 180.000 & 176.400 & 115.000 & 97.000 & 250.500 & 180.000 & 195.500 & 216.250 & 217.500 \\
\hline & Keçi (Kıl) & 19.082 & 18.397 & 15.350 & 15.000 & 6.500 & 4.850 & 2.450 & 9.450 & 9.450 & 9.700 & 4.260 \\
\hline & Toplam & 344.180 & 284.147 & 195.350 & 191.400 & 121.500 & 101.850 & 252.950 & 189.450 & 204.950 & 225.950 & 221.760 \\
\hline \multirow{3}{*}{ Doğubayazıt } & Koyun (Yerli) & 345.376 & 283.248 & 225.700 & 224.000 & 205.000 & 264.000 & 361.800 & 366.900 & 502.000 & 520.000 & 519.000 \\
\hline & Keçi (Kıl) & 20.285 & 19.120 & 23.170 & 21.230 & 19.600 & 23.200 & 40.000 & 40.770 & 45.600 & 43.700 & 39.946 \\
\hline & Toplam & 365.661 & 302.368 & 248.870 & 245.230 & 224.600 & 287.200 & 401.800 & 407.670 & 547.600 & 563.700 & 558.946 \\
\hline \multirow{3}{*}{ Eleşkirt } & Koyun (Yerli) & 187.025 & 148.566 & 89.700 & 75.500 & 76.000 & 49.000 & 36.740 & 41.375 & 62.068 & 42.680 & 49.675 \\
\hline & Keçi (Kıl) & 7.140 & 6.975 & 4.370 & 4.200 & 7.900 & 5.375 & 3.903 & 4.855 & 4.088 & 3.030 & 2.922 \\
\hline & Toplam & 194.165 & 155.541 & 94.070 & 79.700 & 83.900 & 54.375 & 40.643 & 46.230 & 66.156 & 45.710 & 52.597 \\
\hline \multirow{3}{*}{ Hamur } & Koyun (Yerli) & 87.897 & 86.900 & 73.340 & 70.260 & 61.450 & 50.500 & 49.070 & 47.850 & 47.766 & 43.450 & 49.900 \\
\hline & Keçi (Kıl) & 6.030 & 5.870 & 9.300 & 15.780 & 14.765 & 6.650 & 7.150 & 7.010 & 7.500 & 3.910 & 5.170 \\
\hline & Toplam & 93.927 & 92.770 & 82.640 & 86.040 & 76.215 & 57.150 & 56.220 & 54.860 & 55.266 & 47.360 & 55.070 \\
\hline \multirow{3}{*}{ Patnos } & Koyun (Yerli) & 160.954 & 146.400 & 180.800 & 197.000 & 203.000 & 190.300 & 140.000 & 136.200 & 178.500 & 214.000 & 266.000 \\
\hline & Keçi (Kıl) & 7.375 & 7.275 & 6.400 & 7.750 & 4.450 & 13.940 & 25.000 & 37.700 & 41.500 & 46.500 & 37.200 \\
\hline & Toplam & 168.329 & 153.675 & 187.200 & 204.750 & 207.450 & 204.240 & 165.000 & 173.900 & 220.000 & 260.500 & 303.200 \\
\hline \multirow{3}{*}{ Taşlıçay } & Koyun (Yerli) & 117.442 & 104.100 & 151.600 & 115.000 & 97.200 & 91.000 & 81.600 & 70.100 & 69.000 & 36.800 & 85.200 \\
\hline & Keçi (Kıl) & 7.580 & 7.545 & 7.240 & 8.000 & 6.550 & 5.800 & 3.550 & 5.000 & 4.000 & 4.000 & 4.550 \\
\hline & Toplam & 125.022 & 111.645 & 158.840 & 123.000 & 103.750 & 96.800 & 85.150 & 75.100 & 73.000 & 40.800 & 89.750 \\
\hline \multirow{3}{*}{ Tutak } & Koyun (Yerli) & 127.619 & 114.250 & 84.000 & 76.000 & 49.900 & 50.210 & 49.955 & 41.599 & 34.600 & 68.587 & 61.189 \\
\hline & Keçi (Kıl) & 14.900 & 13.700 & 21.000 & 20.200 & 19.450 & 19.580 & 8.055 & 5.794 & 5.350 & 7.080 & 8.360 \\
\hline & Toplam & 142.519 & 127.950 & 105.000 & 96.200 & 69.350 & 69.790 & 58.010 & 47.353 & 39.950 & 75.667 & 69.549 \\
\hline
\end{tabular}




\subsection{Küçükbaş Hayvansal Üretim}

\subsubsection{Et ve Deri Üretimi}

Ağrı’da iktisadi faaliyet büyük ölçüde hayvancılık temellidir. Küçükbaş hayvan yetiştiriciliğinin en önemli üretimi, kuzu ve kuzu etidir. Ağrı İl’i ve Türkiye'de 2004-2014 yılları arasındaki kesilen koyun keçi sayıları, kırmızı et ve deri üretimi Tablo.4'de verilmiştir. Ağrı İl’inde kesilen küçükbaş hayvan sayısına göre, Türkiye küçükbaş kırmızı et ve deri üretimine; 2004 yılında ilin katkısı \% 0.39, \% 0.33, 2009 yılında \% 0.01, \% 0.01'dir [3]. 2010-2014 yılları arasında ortalama \% 3.2, \% 2.9'dur [12]. Bu sonuçlar 2010-2014 yılları arasında bir iyileşmenin varlığını gösterse de, ilin sahip olduğu küçükbaş hayvancılık kapasitesi göz önüne alındığında çok da yeterli olmadığı görülmektedir.

Tablo 4. Ağrı'da ve Türkiye'de Et Üretim (Ton), Kesilen Küçükbaş Hayvan Sayısı (Baş) ve Deri Üretimi (Adet)*

\begin{tabular}{|c|c|c|c|c|c|c|c|c|c|c|}
\hline \multirow[b]{3}{*}{ Yll } & \multicolumn{5}{|c|}{ AĞRI } & \multicolumn{5}{|c|}{ TÜRKIYYE } \\
\hline & \multicolumn{2}{|c|}{ Koyun } & \multicolumn{2}{|c|}{ Keçi } & \multirow{2}{*}{$\begin{array}{c}\text { Küçükbaş } \\
\text { Toplam } \\
\text { Deri } \\
\text { Üretimi } \\
\text { (Adet) }\end{array}$} & \multicolumn{2}{|c|}{ Yerli-Merinos Koyun } & \multicolumn{2}{|c|}{ Yerli-Tiftik Keçi } & \multirow{2}{*}{$\begin{array}{c}\text { Küçükbaş } \\
\text { Toplam } \\
\text { Deri } \\
\text { Üretimi } \\
\text { (Adet) }\end{array}$} \\
\hline & $\begin{array}{l}\text { Kesilen } \\
\text { Hayvan } \\
\text { (Baş) }\end{array}$ & $\begin{array}{l}\text { Et } \\
\text { Üretimi } \\
\text { (Ton) }\end{array}$ & $\begin{array}{c}\text { Kesilen } \\
\text { Hayvan } \\
\text { (Baş) }\end{array}$ & \begin{tabular}{l}
\multicolumn{1}{c}{ Et } \\
Üretimi \\
(Ton)
\end{tabular} & & $\begin{array}{c}\text { Kesilen } \\
\text { Hayvan } \\
\text { (Baş) }\end{array}$ & $\begin{array}{c}\text { Et } \\
\text { Üretimi } \\
\text { (Ton) }\end{array}$ & $\begin{array}{c}\text { Kesilen } \\
\text { Hayvan } \\
\text { (Baş) }\end{array}$ & $\begin{array}{c}\text { Et } \\
\text { Üretimi } \\
\text { (Ton) }\end{array}$ & \\
\hline 2004 & 9.980 & 224 & 4.740 & 91 & 16.037 & 3.933 .973 & 69.715 & 570.512 & 10.300 & 4.860 .588 \\
\hline 2005 & 1.770 & 44 & 482 & 11 & 2.252 & 4.145 .343 & 73.743 & 688.704 & 12.390 & 5.212 .092 \\
\hline 2006 & 1.440 & 32 & 312 & 6 & 1.752 & 4.763 .394 & 81.899 & 803.063 & 14.133 & 6.009 .850 \\
\hline 2007 & 3.838 & 96 & 207 & 4 & 4.045 & 6.428 .866 & 117.524 & 1.256 .348 & 24.136 & 8.178.108 \\
\hline 2008 & 2.041 & 44 & 158 & 3 & 2.199 & 5.588 .906 & 96.738 & 767.522 & 13.752 & 6.853 .219 \\
\hline 2009 & 429 & 10 & 69 & 1 & 498 & 3.997 .348 & 74.633 & 606.042 & 11.675 & 4.952 .822 \\
\hline 2010 & 159.616 & 3.566 & 14.457 & 264 & 174.073 & 6.873 .626 & 135.687 & 1.219 .504 & 23.060 & 8.093 .130 \\
\hline 2011 & 147.766 & 3.301 & 17.225 & 329 & 164.991 & 5.479 .546 & 107.076 & 1.254 .092 & 23.318 & 6.733 .638 \\
\hline 2012 & 177.856 & 3.977 & 18.257 & 338 & 196.113 & 4.541 .122 & 97.334 & 926.799 & 17.430 & 5.467 .921 \\
\hline 2013 & 186.027 & 4.156 & 18.344 & 340 & 204.371 & 4.958 .226 & 102.943 & 1.340 .909 & 23.554 & 6.299 .135 \\
\hline 2014 & 201.945 & 4.507 & 15.940 & 287 & 217.885 & 5.197.289 & 98.978 & 1.570 .239 & 26.770 & 6.767 .528 \\
\hline
\end{tabular}

*ìl verileri 2010-2014 yılları arası [7], diğer veriler [3]'den alınmıştır.

\subsubsection{Süt Üretimi}

2004-2014 yılları arasındaki Ağrı İl’i ve Türkiye’de toplam koyun, keçi sayıları ve süt üretimi değerleri Tablo.5'de verilmiştir [3]. Tablo.5 incelendiğinde il genelinde 2004'den 2009 yılına kadar sağılan koyun keçi sayısı ve üretilen toplam süt miktarında \% 46.4 ve \% 45.7’lik bir azalma, 2009'dan 2014 yılına kadar ise \% 88.2 ve \% 85.4’lük bir artış görülmektedir. Türkiye genelinde ise sağılan toplam hayvan sayısı ve süt üretiminde genel bir artış görülmektedir. 2014 yılı verilerine göre, Türkiye'de sağılan toplam koyun sayısı ve üretilen koyun sütü miktarı içinde, Ağrı İl’inin oranları \% 4.7, \% 4.6, sağılan keçi sayısı ve üretilen keçi sütü miktarında ise \% 0.90, \% 0.93 olarak bulunmuştur. 2014 yılı verilerine göre Ağrı İl'inde sağılan koyun ve keçi başına üretilen süt miktarı sırası ile 75 ve 108 litre/laktasyon dönemi olarak hesaplanmıştır. 2014 yılında İlin, Türkiye koyun keçi toplam sağılan hayvan sayıları ve üretilen süt miktarlarına katkısı ise \% 3.8 ve \% 3.5'dir. Bu sonuçlara bakılarak ilin sahip olduğu sağılan koyun keçi sayıları ve üretilen süt miktarlarının düşük olduğu söylenebilir. 
Şahinler Z., Demir Y.

Tablo 5. Ağrı'da ve Türkiye'de Süt Üretimi (Ton) ve Türlere Göre Sağılan Küçükbaş Hayvan Sayıları (Baş)

\begin{tabular}{|c|c|c|c|c|c|c|c|c|}
\hline & \multicolumn{4}{|c|}{ AĞRI } & \multicolumn{4}{|c|}{ TÜRKIIYE } \\
\hline & \multicolumn{2}{|c|}{ Koyun } & \multicolumn{2}{|c|}{ Keçi } & \multicolumn{2}{|c|}{ Yerli-Merinos Koyun } & \multicolumn{2}{|c|}{ Yerli-Tiftik Keçi } \\
\hline & Sağılan & Süt & Sağılan & Süit & Sağılan & Süt & Sağılan & Süt \\
\hline & $\begin{array}{c}\text { Hayvan } \\
\text { (Baş) }\end{array}$ & $\begin{array}{c}\text { Üretimi } \\
\text { (Ton) }\end{array}$ & $\begin{array}{c}\text { Hayvan } \\
\text { (Baş) }\end{array}$ & $\begin{array}{c}\text { Üretimi } \\
\text { (Ton) }\end{array}$ & $\begin{array}{c}\text { Hayvan } \\
\text { (Baş) }\end{array}$ & $\begin{array}{c}\text { Üretimi } \\
\text { (Ton) }\end{array}$ & $\begin{array}{c}\text { Hayvan } \\
\text { (Baş) }\end{array}$ & $\begin{array}{c}\text { Üretimi } \\
\text { (Ton) }\end{array}$ \\
\hline 2004 & 678.002 & 50.850 & 37.116 & 4.009 & 9.919 .191 & 771.715 & 2.476 .574 & 259.087 \\
\hline 2005 & 580.725 & 43.554 & 35.469 & 3.831 & 10.166 .091 & 789.878 & 2.426 .993 & 253.759 \\
\hline 2006 & 534.890 & 40.117 & 40.140 & 4.335 & 10.245 .895 & 794.681 & 2.420 .642 & 253.759 \\
\hline 2007 & 514.153 & 38.561 & 41.742 & 4.508 & 10.109.987 & 782.587 & 2.263 .629 & 237.487 \\
\hline 2008 & 358.225 & 26.867 & 35.757 & 3.862 & 9.642 .170 & 746.872 & 1.997 .689 & 209.570 \\
\hline 2009 & 349.058 & 26.179 & 34.506 & 3.727 & 9.407 .866 & 734.219 & 1.830 .814 & 192.210 \\
\hline 2010 & 595.052 & 44.629 & 36.143 & 3.903 & 10.583 .608 & 816.832 & 2.582 .539 & 272.811 \\
\hline 2011 & 525.123 & 39.384 & 44.572 & 4.814 & 11.561 .144 & 892.822 & 3.033 .111 & 320.588 \\
\hline 2012 & 712.597 & 53.445 & 48.177 & 5.203 & 13.068 .428 & 1.007 .007 & 3.502 .272 & 369.429 \\
\hline 2013 & 732.886 & 54.966 & 49.173 & 5.311 & 14.287 .237 & 1.101 .013 & 3.943 .318 & 415.743 \\
\hline 2014 & 681.983 & 51.149 & 39.861 & 4.305 & 14.524 .264 & 1.113 .937 & 4.400 .168 & 463.270 \\
\hline
\end{tabular}

\subsubsection{Yapağı ve Kıl Üretimi}

Türkiye ve Ağrı İl'inde 2004-2014 yılları arasındaki yapağı ve kıl-tiftik üretimi Tablo.6'da verilmiştir [3]. Tablo.6 incelendiğinde 2004'den 2009 yılına kadar Ağrı İl'inde, kırkılan koyun keçi sayıları ve elde edilen yapağı ve kıl miktarlarında sırasıyla \% 43.0, \% 2.4 ve \% 43.0, \% 3.0 oranlarında düşüş, 2009'dan itibaren ise kırkılan koyun keçi sayıları ve elde edilen yapağı ve kıl miktarlarında sırasıyla $\% 27, \% 41$ ve \% 26, \% 41 oranlarında artışlar görülmektedir. Türkiye genelindeki durum ise, 2004'den 2009 yılına kadar, toplam kırkılan koyun keçi sayıları ve elde edilen yapağı ve kıl-tiftik miktarlarında sırasıyla \% 14, \% 27 ve \% 12, \% 28 oranlarında bir düşüş, 2009'dan itibaren ise kırkılan koyun keçi sayıları ve elde edilen yapağı ve kıl-tiftik miktarlarında sırasıyla \% 43, \% 170 ve \% 45, \% 164 oranlarında artışlar olmuştur. Genel olarak küçükbaş kırkılan hayvan sayıları ve elde edilen yapağı ve kıltiftik miktarları bakımından düşüş ve artışlar, Ağrı İl’i ile Türkiye arasında benzerlik gösterse de, artış oranları bakımından Ağrı İl'inin Türkiye'nin oldukça gerisinde kaldığı görülmektedir. 2014 yılı itibarı ile İlin, Türkiye toplam küçükbaş kırkılan hayvan sayıları ve elde edilen toplam yapağı ve kıl-tiftik miktarlarına katkısı sırasıyla \% 3.6 ve \% 4.0 olmuştur. İlin sahip olduğu küçükbaş hayvancılık potansiyeline göre, küçükbaş kırkılan hayvan sayıları ve elde edilen yapağı ve kıl-tiftik miktarları bakımından da ilin katkısının yetersiz olduğu düşünülmektedir. 
Tablo 6. Ağrı'da ve Türkiye'de Kırkılan Küçükbaş Hayvan Sayıları (Baş) ve Yapağı, Kıl-Tiftik Üretimleri (Ton)

\begin{tabular}{|c|c|c|c|c|c|c|c|c|}
\hline & \multicolumn{4}{|c|}{ AĞRI } & \multicolumn{4}{|c|}{ TÜRKIYYE } \\
\hline & \multicolumn{2}{|c|}{ Yerli Koyun } & \multicolumn{2}{|c|}{ Kıl Keçi } & \multicolumn{2}{|c|}{ Yerli-Merinos Koyun } & \multicolumn{2}{|c|}{ Kıl-Tiftik Keçi } \\
\hline & $\begin{array}{c}\text { Kırkılan } \\
\text { Hayvan } \\
\text { (Baş) }\end{array}$ & $\begin{array}{c}\text { Yün } \\
\text { (Ton) }\end{array}$ & $\begin{array}{c}\text { Kırkılan } \\
\text { Hayvan } \\
\text { (Baş) }\end{array}$ & $\begin{array}{c}\text { Kıl } \\
\text { (Ton) }\end{array}$ & $\begin{array}{c}\text { Kırkılan } \\
\text { Hayvan } \\
\text { (Baş) }\end{array}$ & $\begin{array}{c}\text { Yün } \\
\text { (Ton) }\end{array}$ & $\begin{array}{c}\text { Kırkılan } \\
\text { Hayvan } \\
\text { (Baş) }\end{array}$ & $\begin{array}{c}\text { Kıl-tiftik } \\
\text { (Ton) }\end{array}$ \\
\hline 2004 & 1.571 .971 & 2.932 & 66.215 & 33 & 25.201 .155 & 45.972 & 4.719 .879 & 3.019 \\
\hline 2005 & 1.352 .664 & 2.523 & 63.075 & 31 & 25.304 .325 & 46.176 & 4.602 .245 & 2.956 \\
\hline 2006 & 1.265 .140 & 2.359 & 81.130 & 40 & 25.616.912 & 46.776 & 4.686 .220 & 3.002 \\
\hline 2007 & 1.200 .760 & 2.239 & 80.850 & 40 & 25.462 .293 & 46.752 & 4.343 .942 & 2.773 \\
\hline 2008 & 990.270 & 1.847 & 66.445 & 33 & 23.974 .591 & 44.166 & 3.851 .143 & 2.432 \\
\hline 2009 & 892.510 & 1.665 & 64.612 & 32 & 21.749 .508 & 40.270 & 3.454 .530 & 2.176 \\
\hline 2010 & 1.064 .105 & 1.985 & 74.578 & 37 & 23.089.691 & 42.823 & 4.570 .442 & 2.807 \\
\hline 2011 & 985.104 & 1.837 & 86.297 & 43 & 25.031 .565 & 46.586 & 5.295 .664 & 3.256 \\
\hline 2012 & 1.185 .709 & 2.211 & 94.323 & 47 & 27.425 .233 & 51.180 & 6.130 .105 & 3.769 \\
\hline 2013 & 1.240 .180 & 2.313 & 122.295 & 61 & 29.284 .247 & 54.784 & 8.398 .422 & 5.162 \\
\hline 2014 & 1.346 .303 & 2.511 & 105.169 & 52 & 31.140 .244 & 58.403 & 9.328 .746 & 5.741 \\
\hline
\end{tabular}

\subsubsection{Dane Yem ve Yem Bitkileri Üretimi}

Küçükbaş hayvanların beslenmesine ilişkin sorunlara bakıldığında öncelikle kaliteli kaba yem açığı sorunu öne çıkmaktadır. Ağrı İl’inde genelde üretimi yapılan buğday, arpa, fiğ, korunga, yonca ve silajlık mısırın 2004-2014 yılları arası üretim miktarları Tablo.7'de verilmiştir [10]. İlin buğday (dane), arpa (dane), fiğ (yeşil ot), korunga (yeşil ot), yonca (yeşil ot) ve silajlık mısır üretimi bakımından 2014 yılında Türkiye'deki payı sırasıyla $\% 0.9, \% 1.4, \% 0.9$, $\%$ 4.8, $\% 4.7$ ve $\% 0.08$ oranlarında olmuştur.

Tablo 7. Ağrı İl’i Buğday, Arpa, Fiğ, Korunga, Yonca Üretimi (ton)

\begin{tabular}{|c|c|c|c|c|c|c|c|c|c|c|c|c|}
\hline \multirow{2}{*}{ Yillar } & \multicolumn{2}{|c|}{$\begin{array}{l}\text { Buğday } \\
\text { (Dane) }\end{array}$} & \multicolumn{2}{|c|}{$\begin{array}{l}\text { Arpa } \\
\text { (Dane) }\end{array}$} & \multicolumn{2}{|c|}{$\begin{array}{c}\text { Fiğ } \\
\text { (Yeşil Ot) }\end{array}$} & \multicolumn{2}{|c|}{$\begin{array}{l}\text { Korunga } \\
\text { (Yeşil Ot) }\end{array}$} & \multicolumn{2}{|c|}{$\begin{array}{c}\text { Yonca } \\
\text { (Yeşil Ot) }\end{array}$} & \multicolumn{2}{|c|}{ Mısır (Silajlık) } \\
\hline & $\begin{array}{l}\text { Ekili } \\
\text { Alan } \\
\text { (da) }\end{array}$ & $\begin{array}{l}\text { Üretim } \\
\text { (Ton) }\end{array}$ & $\begin{array}{l}\text { Ekili } \\
\text { Alan } \\
\text { (da) }\end{array}$ & $\begin{array}{c}\text { Üretim } \\
\text { (Ton) }\end{array}$ & $\begin{array}{l}\text { Ekili } \\
\text { Alan } \\
\text { (da) }\end{array}$ & $\begin{array}{c}\text { Üretim } \\
\text { (Ton) }\end{array}$ & $\begin{array}{l}\text { Ekili } \\
\text { Alan } \\
\text { (da) }\end{array}$ & $\begin{array}{c}\text { Üretim } \\
\text { (Ton) }\end{array}$ & $\begin{array}{l}\text { Ekili } \\
\text { Alan } \\
\text { (da) }\end{array}$ & $\begin{array}{l}\text { Üretim } \\
\text { (Ton) }\end{array}$ & $\begin{array}{l}\text { Ekili } \\
\text { Alan } \\
\text { (da) }\end{array}$ & $\begin{array}{c}\text { Üretim } \\
\text { (Ton) }\end{array}$ \\
\hline 2004 & 1.566 .240 & 168.413 & 545.570 & 76.570 & 16.260 & 2.751 & 29.720 & 18.231 & 123.770 & 97.072 & 410 & 2.250 \\
\hline 2005 & 1.512 .740 & 163.995 & 580.680 & 91.280 & 15.800 & 3.975 & 41.980 & 13.654 & 146.490 & 81.480 & 560 & 3.027 \\
\hline 2006 & 1.146 .396 & 133.818 & 539.993 & 81.788 & 137.928 & 13.823 & 52.070 & 18.828 & 409.100 & & 1.406 & 6.415 \\
\hline 2007 & 994.908 & 141.607 & 555.904 & 101.096 & 152.628 & 52.833 & 42.188 & 23.732 & 600.651 & 311.952 & 1.393 & 6.789 \\
\hline 2008 & 990.068 & 123.080 & 332.789 & 50.113 & 121.703 & 47.381 & 114.363 & 43.820 & 885.832 & 344.454 & 1.275 & 6.525 \\
\hline 2009 & 963.927 & 175.297 & 488.479 & 98.615 & 67.000 & 39.600 & 85.200 & 44.060 & 841.500 & 428.750 & 1.900 & 8.600 \\
\hline 2010 & 1.006.377 & 181.955 & 507.000 & 103.840 & 51.258 & 41.378 & 81.000 & 67.850 & 784.000 & 1.259 .900 & 925 & 5.075 \\
\hline 2011 & 1.078 .044 & 182.473 & 489.000 & 80.135 & 60.900 & 46.710 & 76.550 & 51.490 & 668.900 & 790.040 & 675 & 3.700 \\
\hline 2012 & 1.048 .510 & 166.666 & 460.500 & 71.726 & 68.198 & 30.963 & 116.259 & 49.179 & 739.913 & 730.386 & 1.220 & 4.730 \\
\hline 2013 & 1.092 .573 & 211.580 & 491.200 & 102.069 & 63.555 & 42.555 & 128.300 & 84.051 & 679.100 & 990.910 & 2.885 & 14.805 \\
\hline 2014 & 1.091 .207 & 169.704 & 470.635 & 86.820 & 70.600 & 37.712 & 141.100 & 78.297 & 695.883 & 628.460 & 2.990 & 14.020 \\
\hline
\end{tabular}

Toplam yem bitkileri (fiğ-yeşil ot, korunga-yeşil ot, yonca-yeşil ot ve silajlık mısır) üretimi olarak ilin 2014 yılında Türkiye'deki payı (39.994.851 ton) \% 2.8'dir. 
Tablo.7 incelendiğinde, dane yemlerden buğday üretiminde 2004'den 2008'e doğru bir düşüş, 2009'dan 2014'e doğru hafif bir artış gözlenirken, arpada en düşük üretim 2008'de (50.113 ton), en yüksek üretim ise 2010 yllında (103.840 ton) olarak gerçekleşmiştir. Yem Bitkileri fiğ (yeşil ot), korunga (yeşil ot), yonca (yeşil ot) ve silajlık mısır toplam üretimlerinde 2004'den (120.304 ton), 2014'e (758.489 ton) \% 530 oranında bir artış gerçekleşmiştir. Bu artışlarda yem bitkilerine uygulanan desteklerin 18.4.2006 tarihli ve 5488 sayılı Tarım Kanununun 19. maddesi Yem Bitkileri Desteklemelerinin düzenlenmesi ve uygulanmasıyla, dane yem üretim alanları ve üretiminin azalması, yem bitkileri alanları ve üretiminin artmasında önemli bir katkı sağladığı düşünülmektedir [13].

\section{Sonuç ve Öneriler}

İlde tespit edilen küçükbaş hayvancılığın başlıca sorunları şöylece sıralanabilir: 1- Küçükbaş hayvan yetiştiricilerinin başlıca üretimi olan kuzunun, katma değeri yüksek et veya ürünleri olarak değerlendirilemeyip canlı hayvan olarak pazara arz edilmesi,

2- Sürülerde koç katım aralığına bağlı olarak, yetiştirilen kuzu sürülerindeki kuzular arası yaş farkı dolayısıyla canlı ağırlık ve gelişme farkı olan küçük, kesime uygun olmayan kuzular vardır. Mera dönüşü sürülerin toplu satışlarında bu kuzuların da satılmasıyla üretim kayıplarına neden olması,

3- Mera dönüşü satış arzının yüksek olması sebebiyle, üretici satış fiyatlarının üretici aleyhinde oluşması,

4- Sürü yönetimi, alternatif olacak koyun ırkları ve biyogüvenlik tedbirleri ile ilgili yetiştiricilerin teorik ve pratik bilgi eksikliğinin olması,

5- Bakıcı ve çoban ihtiyacının karşılanamaması,

6- Sürü sağı̆ğını korumada personel ve hizmetin yeterli olmaması,

7- İldeki küçükbaş hayvan yetiştiricilerinin uygulanan hayvancılık politikalarını yeterli bulmaması,

8- Verilen hibe ve kredilerin küçükbaş hayvancılığın amacı dışındaki yatırımlarda kullanma eğiliminin olmas1,

9- Kü̧̈ükbaş hayvan yetiştiricilerinin sosyal statüleri ile ilgili olumsuzluklardan dolayı, genç nüfusun hayvancılı̆ga ilgi duymaması,

10- Son yıllardaki yüksek yem maliyetlerinden dolayı sürü büyüklüklerindeki ciddi azalmalar hatta yetiştiriciliğin terkedilmesi,

11-Sektörün bileşenleri olan, üreticiler ve birlikleri, bakanlık ve teşkilatları, üniversite, AR-GE kurum ve kuruluşları, sanayii kurum ve kuruluşlarının uyumlu ve organize çalışma eksikliklerinin olması,

Yukarda belirlenen sorunların çözümü ile ilgili öneriler şu şekilde özetlenebilir:

1- Etin pazarlanmasında pazarlama ağlarının kurulması, bu ağların kurulmasında ruhsatlı kesim yerlerinin ve bu yerlerin denetimlerinin artırılması, et ve süt kurumunun piyasa düzenleme etkinliğinin artırılması, 2- İşletmelerin ihtiyacı olan bakıcı ve çoban eğitim kurslarının düzenlenmesi ve sertifikalandırılması ile sertifikalı çoban ve bakıcının sağlık sigortalarının devlet tarafından desteklenmesi, bu konudaki mevcut uygulamaların geliştirilmesi,

3- Yem bitkileri üretiminde devlet desteğinin artırılması ve verim artırıcı uygulamaların sahaya yansıtılması, uygulamadaki eksik ve zayıf yönlerin giderilmesi,

4- Hibe ve teşviklerin kullandırılmasında, üretici seçiminin ilgili kuruluşlar tarafından daha titiz değerlendirilmesi, 
5- Bölgedeki sektörle ilgili kuruluşların teknik personelce desteklenmesi üretici ve kurumlar arasında bilgi akışının güçlenmesine yönelik plan ve programların yapılması,

6-Bölgede önder üreticilerin seçilerek kültür ırkı ve melez yetiştiricilikte çekirdek sürülerin kurulması, işletme bazında üretim ekonomisinin değerlendirilmesi, sonuçlarının tabana yayılması ve üretici örgütlerinin daha etkin hale getirilmesi,

7-Gelişmiş ülkelerde olduğu gibi, yapilacak teknolojik çalışmalarla küçükbaş hayvansal ürünlerin kalitesinin ve çeşitliliğinin artırılıp yurt içinde, yurt dışında tanıtımının yapılarak tüketiminin ve ihracatının özendirilmesi, böylece bir yandan küçükbaş hayvansal ürünlerin ve yetiştirici gelirlerinin artması sağlanırken, bir yandan da ihracat gelirlerinin artmasının sağlanması,

8- Ağrı İl’inde yetiştirilen Morkaraman ırkı yüksek verimli genotiplerinden, birlik ve tarım işletmesi vb. bünyesinde çekirdek anaç sürü ve koç istasyonlarının kurulması, böylece üreticinin ihtiyacı olan damızlık materyalin sağlanması,

9- Ağrı İl’inde organik kuzu üretim alt yapısının oluşturulması, (Gıda, Tarım ve Hayvancılık Bakanlığı, TAGEM Genel Müdürlüğünün koordinatörlüğünde yürütülen 'Halk Elinde Kü̧̈ükbaş Hayvan Islahı Ülkesel Projesi’ndeki sürülerde bu uygulama başlatılabilir),

10- Örnek ve ihtisaslı işletmelerin kurulması,

11- Yetiştiriciler için yurt içi ve yurt dişı teknik geziler düzenlenerek, üretici bilgi, uygulama ve motivasyonunun artırılmasının sağlanması,

12- Hayvan sağlığı ve hastalıklarıyla mücadele, sürü yönetimi ile ilgili mobil eğitim kurslarının düzenlenmesi,

13- Koyun Keçi birliklerinin, profesyonel pazarlama ve üretim organizasyonu yapısına dönüştürülmesi ve üretici ile tüketicinin güvenini kazanacak uygulamaları yapabilecek statüye kavuşturulması,

14-Sektörün bileşenleri olan, üreticiler ve birlikleri, bakanlık ve teşkilatları, üniversite, AR-GE kurum ve kuruluşları, sanayii kurum ve kuruluşları problemlerin çözümü konusunda işbirliğini artırmalıdırlar.

Bu çözüm önerilerinin hayata geçirilmesiyle, sahip olunan küçükbaş hayvan varlığı potansiyeline uygun, başta Ağrı İl’i olmak üzere, Türkiye'de genelde hayvancıllğın özelde ise küçükbaş hayvancılığın gelişmesine çok önemli katkılar sağlayacağı düşünülmektedir.

\section{Kaynaklar}

[1] Tıknazoğlu B., "Sığırcılık”, Samsun İl Tarım Müdürlüğü Çiftçi Eğitimi ve Yayım Şubesi Yayını, 2010.

[2] Kaymakçı M., ve ark., "Türkiye de küçükbaş hayvan yetiştiriciliği”, Türkiye Ziraat Mühendisliği V. Teknik Kongresi 2, Ankara, 17-21Ocak 2000.

[3] TÜIK, "Türkiye İstatistik Kurumu, https://biruni.tuik.gov.tr/hayvancilikapp/hayvancilik.zul”, Erişim Tarihi 25.11.2015.

[4] Bingöl, M., Yılmaz, A., Daşkıran, İ., M., Vural, M., "Doğu Anadolu Bölgesinde organik koyun yetiştiriciliği ve geliştirme olanakları", Bitlis Eren Üniversitesi Fen Bilimleri Dergisi, 2(1), 98108, 2013. 
[5] Karaca O., Odabaşığlu F., Altın T., Söğüt B., Kaygısız A., "Doğu Anadolu hayvancılığının yapısal özellikleri ve geliştirilmesi olanakları”, Hayvancılık’96 Ulusal Kongresi, 168s, 18-20 Eylül, İzmir, 1990.

[6] Ertuğrul, M., Savaş, T., Dellal, G., Taşkın, T., Koyuncu, M., Cengiz, F., Dağ, B., Koncagül, S., Pehlivan, E., “Türkiye küçükbaş hayvancılığının iyileştirilmesi”, Ziraat Mühendisliği VII. Teknik Kongresi, s. 667-685,11-15, Ankara, 2010.

[7] Karaca O., Kaymakçı M., “Güneydoğu Anadolu'da hayvancılığın geliştirilmesi için kimi öneriler”, Hayvansal Üretim Dergisi, 35: 9, 1994.

[8] Anonim, “Ağrı İl Gıda, Tarım ve Hayvancılık Müdürlüğü Faaliyet Raporu”, http://agri.tarim.gov.tr/Menu/2/Faaliyet-Raporlari, Erişim Tarihi 25.11.2015.

[9] Anonim, “Ağrı Tarım ve Hayvancılık Çalıştayı Sonuç Raporu”, sa. 86-88,2014.

[10] TÜİK, “Türkiye İstatistik Kurumu https://biruni.tuik.gov.tr/bitkiselapp/bitkisel.zul”, Erişim Tarihi 25.11.2015

[11] Sarıcan, C., Karaca, O., "Doğu Anadolu Bölgesi koyunculuğunun yapısal özellikleri ve geliştirilmesi olanakları”, Et ve Balık Endüstrisi Dergisi, Cilt : 9, Sayı : 57, 1989.

[12] Anonim, “Ağrı İl Gıda, Tarım ve Hayvancılık Müdürlüğü”, 2014.

[13] Yolcu, H., Tan, M., “Ülkemiz yem bitkileri tarımına genel bir bakış”, Ankara Üniversitesi Ziraat Fakültesi Tarım Bilimleri Dergisi, 14 (3): 303-312, 2008. 